\title{
Cytoblock preparations for examination of cervical and other cells
}

\author{
B Dagg, D L S Eustace, X Han, S Money, E Heyderman
}

\begin{abstract}
There are a number of antibodies which may be of value in the investigation of cervical smears, effusions, and cells grown in monolayer culture. The Shandon Cytoblock method was used to prepare discs of such cells suitable both for diagnosis and for a variety of other techniques.
\end{abstract}

(F Clin Pathol 1992;45:1122-1123)

Cervical smears stained by the Papanicolaou technique have the advantages of speed, simplicity, and familiarity. Considerable experience has been built up in their interpretation, and though there are problems with inter- and intra-observer error, ${ }^{1}$ in those countries in which screening programmes have been widely implemented there has been a considerable fall in incidence of cervical carcinoma and mortality. $^{2}$ Smears have the disadvantage of being unique so that if several immunostains are to be performed there will be considerable differences in cell populations between slides made at the same time from the same scrape. The epithelial cells may be obscured by pus in the presence of severe inflammation, or the smear may be too thick to interpret.

\section{Methods}

The efficacy of the Shandon Cytoblock method (Shandon, Cheshire) for the evaluation of cervical cytology was investigated with a view to using the preparations for imunocytochemical techniques. Specimens were

Accepted for publication 8 July 1992

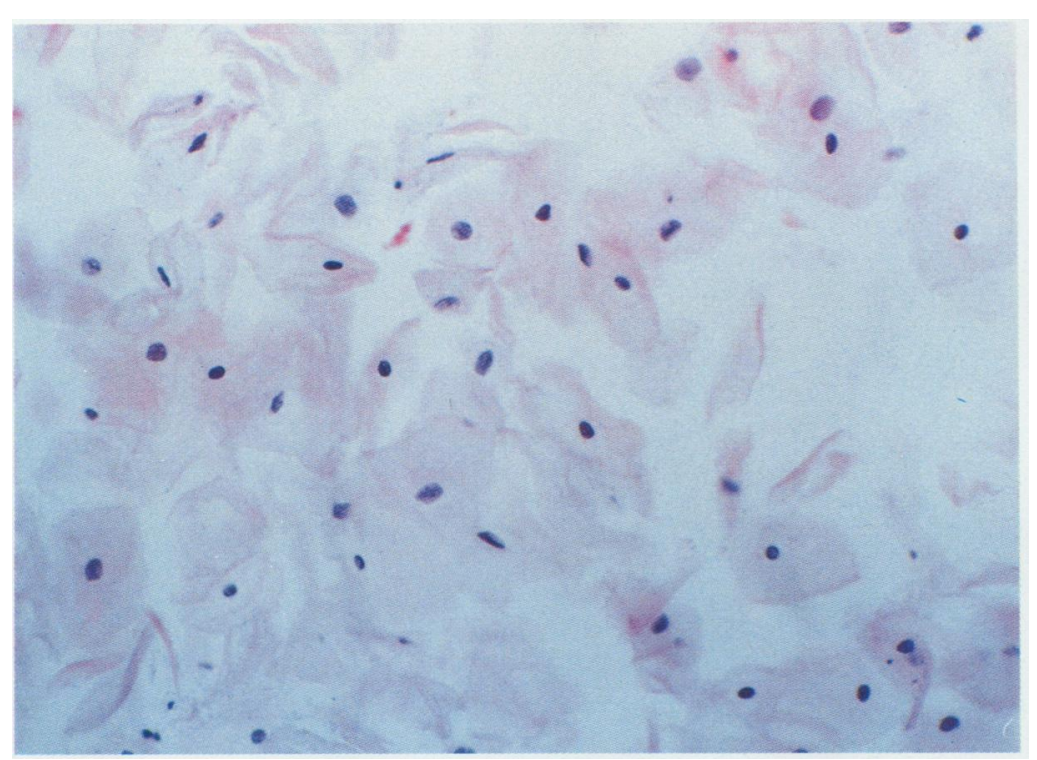

Figure 1 Normal smear. Most of the squames are cut as non-overlapping single cells. obtained from 28 unselected patients referred to a colposcopy clinic because of an abnormal smear result. A Cervex brush (Vernacare, Lancs) which has a gently concave flattened portion that brushes the external cervix, and a pointed centre that samples the upper portion of the endocervical canal, was used. ${ }^{3}$

The brush head was detached by pushing it off manually and put into unbuffered $10 \%$ formalin in a Universal container. The container was shaken to dislodge as many cells as possible, and centrifuged at $1000 \mathrm{rpm}$ for three minutes. The brush floated to the surface and was discarded, and the pellet was spun down in the same container at $3000 \mathrm{rpm}$ for a further 10 minutes. The formalin was poured off and the pellet resuspended by vortexing in four drops of the gelling reagent (Reagent 2 of the Cytoblock kit). The cell disc was prepared by centrifuging the cells into the embedding cassette according to the manufacturer's instructions. It was then routinely processed to paraffin wax and folded in half before embedding to obtain maximum thickness for sectioning.

Sections were cut at $4 \mu \mathrm{m}$ and were stained with haematoxylin and eosin. Unstained sections were mounted on silane treated slides and immunostained with our murine monoclonal antibody TDM39 raised against the XH1 cervical carcinoma cell line. ${ }^{4}$ A streptavi$\mathrm{din} /$ biotin/peroxidase technique ${ }^{5}$ with a rabbit anti-mouse biotinylated second antibody (Dako, Bucks) was used. Endogenous peroxidase was inhibited as described previously. ${ }^{6}$

\section{Results}

Twenty five out of 28 of the sections contained sufficient cervical epithelial cells for diagnosis and 14 also contained strips of either squamous or endocervical cells or both (figs 1,2 and 3). Three contained too few cells for diagnosis. Four others had not been cut into deeply enough, but with further experience this proportion should decrease. However, we would prefer to cut deeper levels as required, rather than risk wasting previous material by cutting too far into the block to begin with. One further block contained relatively few cells even when cut deeper, but as these showed severe dysplasia the preparation was considered satisfactory. Twelve blocks contained pus, often in large sheets, which might have made a conventional smear difficult to interpret. In the Cytoblock sections sufficient epithelial cells for diagnosis were seen between the sheets of polymorphs (fig 3). There was satisfactory immunostaining with our TDM39 antibody (fig 4). 


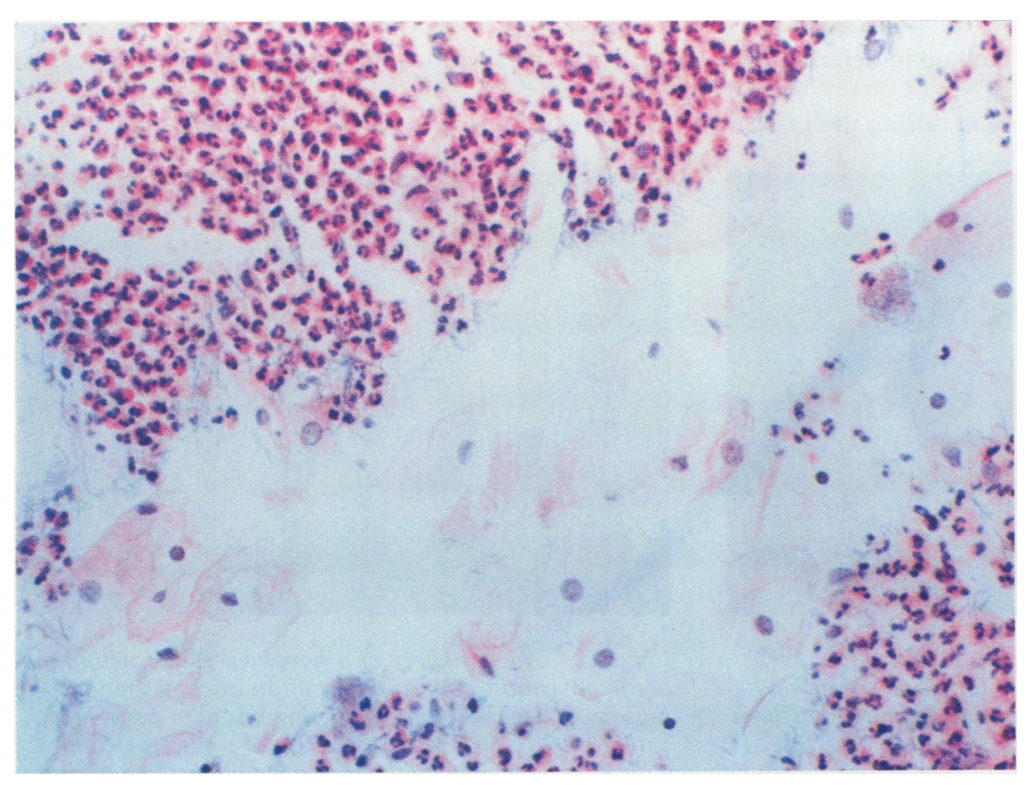

Figure 2 Sheets of polymorphs surround squames showing some reactive nuclear enlargement but no dysplasia.

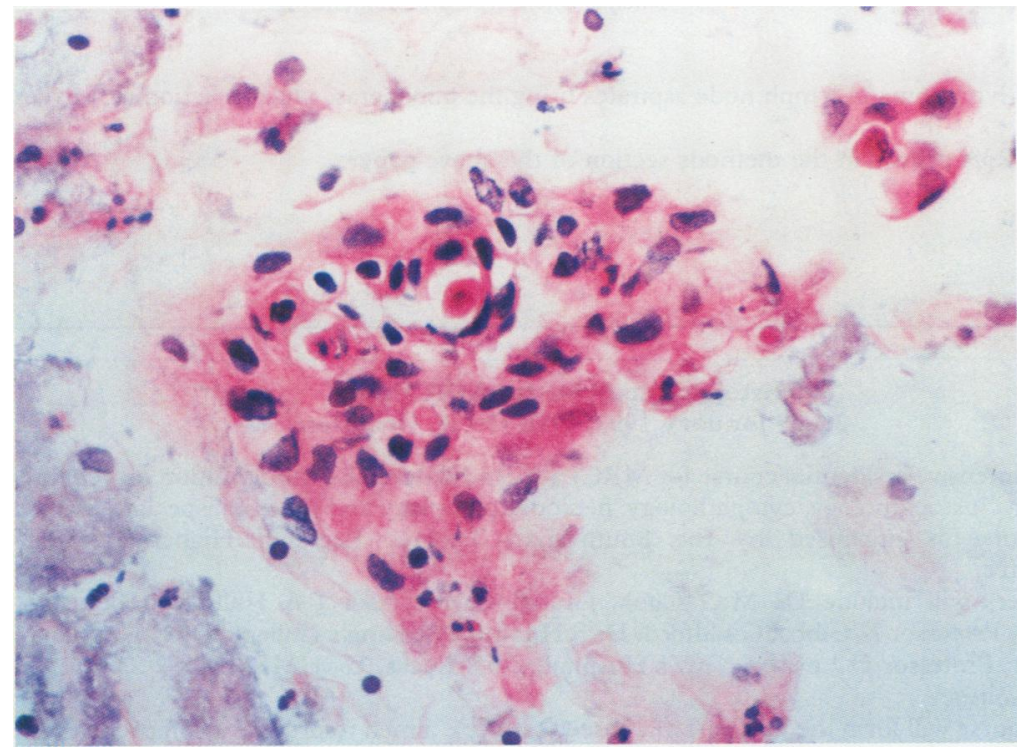

Figure 3 There is a sheet of koilocytic dysplastic focally keratinising cervical cells in the centre. Surrounding this there is a mixture of dysplastic cells, cells showing inflammatory change, normal mature cells, and a few polymorphs.

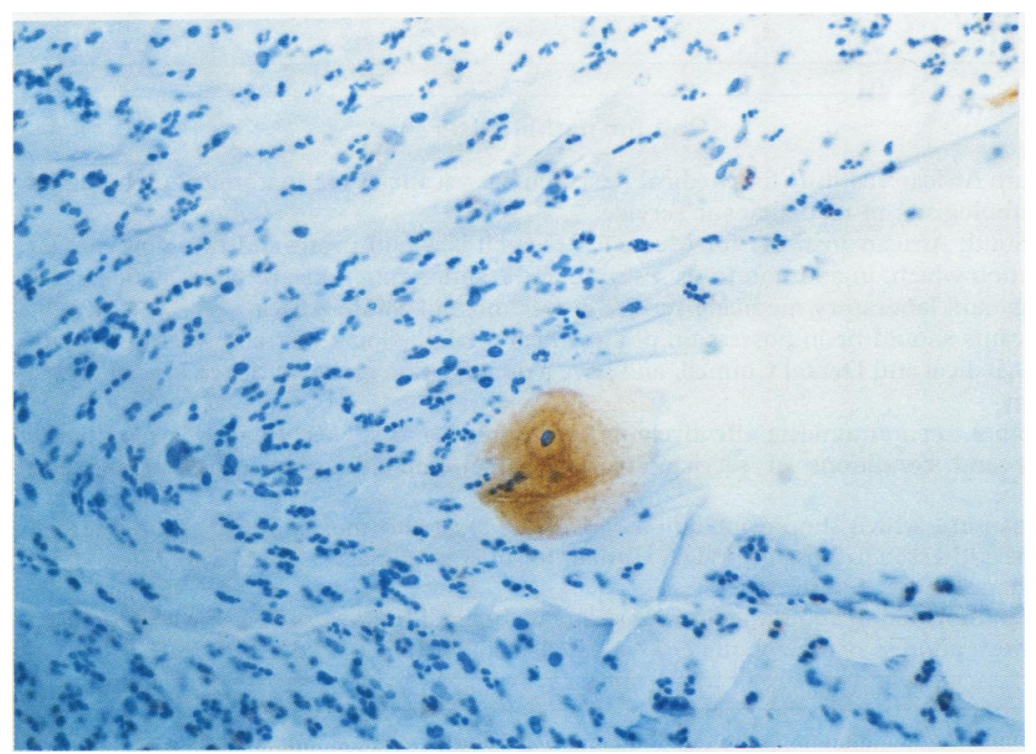

Figure 4 Inflamed smear immunostained with TDM39 antibody using an ABC peroxidase technique. Two overlapping squames with perinuclear haloes in the centre are positive, normal squames among the inflammatory cells are negative, while occasional polymorphs are weakly positive.

\section{Discussion}

Cytoblock preparations are easier to prepare than cell pellets using agar or gelatin. ${ }^{7}$ Both of these reagents have to be specially prepared and kept warm. The cells need to be centrifuged, the agar or gelatin added, and when set it is sometimes quite difficult to scrape out the pellet, and those at the bottom of the centrifuge tube may be left behind. When the agar or gelatin block is processed and therefore warmed again, the cells often disperse around the edges, and it is difficult to control the size of the block. When Cytoblocks are used the blocks are of small uniform size, reduced quantities of reagents can be used, and immunostaining is more easily standardised. In a preliminary experiment we used direct cytospin preparations, but each preparation from the same scrape was potentially different from the next, and only a limited number could be made from each sample. Laboratories with an up-to-date Cytospin will already have the stainless steel clips that hold the special cassette and loading funnel. The fixing and gelling reagents, the embedding cassette and Cytofunnel presently cost $84 \mathrm{p}$ a block. However, the method is more satisfactory and reproducible and somewhat less time consuming than the preparation of agar or gelatin blocks. Though these cost only $10 \mathrm{p}$ a block, they are less satisfactory especially when the sample is scanty.

Cytoblock preparations made by this method can be used for haematoxylin and eosin staining and immunostaining in the same way as normal paraffin wax embedded cell pellets or tissue blocks. To characterise our cervical carcinoma cell lines and nude mouse xenografts, we carried out total genomic DNA in situ hybridisation on Cytoblock sections to distinguish between murine and human cells. In situ hybridisation may also be used for human papillomavirus subtyping. Double labelling, to demonstrate a variety of antigens in the same section, can also be performed on these preparations. A prospective study comparing conventional smears, Cytoblock preparations, colposcopic findings and biopsy specimens is under way and will be reported elsewhere.

This work was supported by the Jean Shanks Foundation (BD), Birthright (DLSE), the Dunhill Medical Trust (XH), and the S Thomas's Hospital Research Endowments Fund (SM).

1 Van der Graaf Y, Vooijs GP, Gaillard HLJ, Go DMDS. Screening errors in cervical cytologic screening. Acta Cytol 1987;4:434-8.

2 Day NE. Screening for cancer of the cervix. 7 Epidemiol Commun Health 1989;43:103-6.

3 Waddell CA, Rollason TP, Amarilli JM, Cullimore J, McConkey CC. The cervex: an ectocervical brush sampler. Cytopathology 1990;1:171-81.

4 Han X, Lyle R, Eustace DLS, et al. XH1-a new cervical carcinoma cell line and xenograft model of invasion, 'metastasis' and regression Br f Cancer 1991;64:645-54.

$5 \mathrm{Hsu}$ S-M, Raine L, Fanger $H$. Use of avidin-biotinperoxidase complex (ABC) in immunoperoxidase techniques: A comparison between ABC and unlabelled antibody (PAP) procedures. $\mathcal{f}$ Histochem Cytochem 1981;29:577-85.

6 Heyderman E. Immunoperoxidase technique in histopathology: applications, methods, and controls. $\mathcal{f}$ Clin Pathol 1979;32:971-8.

7 Heyderman E, Ebbs SR, Larkin SE, Brown BME, Haines AMR, Bates T. Response of breast carcinoma to endocrine therapy predicted using immunostained pelleted crine therapy predicted using immunostained pell

8 Obara T, Conti CJ, Baba M, Resau JH, Trifillis A L, Trump BF, Klein-Szanto AJP. Rapid detection of xenotransBF, Klein-Szanto AJP. Rapid detection of xenotrans-
planted human tissues using in situ hybridization. $A m \mathcal{F}$ planted human tissues using
Pathol 1986;122:386-91. 